\title{
Retinoic Acid Inhibits Uterotrophic Activity of Bisphenol A in Adult Ovariectomized Rats
}

\author{
Tomoko KoDA ${ }^{1,2}$, Masatoshi MoRITA ${ }^{2,3}$ and Hideki IMAI ${ }^{1,2}$ \\ ${ }^{1}$ Division of Environmental Health Sciences, Department of Social Medicine, Faculty of Medicine, University \\ of Miyazaki, 5200 Kihara, Kiyotake, Miyazaki 889-1692, Japan \\ ${ }^{2}$ National Institute for Environmental Studies, 16-2 Onogawa, Tsukuba, Ibaraki 305-8506, Japan \\ ${ }^{3}$ Department of Bioresources, Faculty of Agriculture, Ehime University, 3-5-7 Tarumi, \\ Matsuyama, Ehime 790-8566, Japan \\ (Received November 24, 2006)
}

\begin{abstract}
Summary Bisphenol A (BPA) is used in the production of polycarbonate and epoxy resins. The weak estrogenic activity of BPA has been confirmed by both in vitro and in vivo assays. Retinal acetate has been reported to inhibit the adverse effects of BPA on male mice reproduction. All-trans-retinoic acid (ATRA) is a potent natural derivative of vitamin A and is reported to inhibit the estrogen-induced proliferation of human breast carcinoma cells. In this study, we investigated the possible inhibitory effects of ATRA on the estrogenic activity of BPA by a standard in vivo uterotrophic assay. Proliferated and apoptotic uterine cells were identified by 5 -bromo-2'deoxyuridine (BrdU) incorporation and terminal deoxynucleotidyl transferase (TdT)-mediated dUTP nick end labeling (TUNEL) assay. We observed that ATRA supplementation significantly inhibits a BPA-induced uterine weight increase in adult ovariectomized rats. However, there were no significant differences in the increases in the numbers of BrdU-positive cells and TUNEL-positive cells between the BPA and BPA+ATRA groups. These results show that ATRA may have an inhibitory effect on the estrogenic activity of BPA in an in vivo assay.
\end{abstract}

Key Words retinoic acid, bisphenol A, uterotrophic assay, in vivo, rat

Bisphenol A (BPA) has been widely used in the manufacture of polycarbonate, epoxy resins (1), fungicides, antioxidants, dyes, flame retardants and several types of dental sealant (2). Bisphenol A can be released from polycarbonate flasks during autoclaving (3) and from lacquer coatings inside food cans (4). Bisphenol A has a weak estrogenicity (5). It was found to bind to the human estrogen receptor (ER) (6) and to induce the proliferation of MCF-7 cells $(3,4)$ and the transcriptional activation of the ER in a yeast-based assay (7).

Vitamin A and its retinoid derivatives have profound effects on cellular proliferation and differentiation (8). All-trans-retinoic acid (ATRA) is the primary active metabolite of vitamin A $(9,10)$ and also the most biologically active retinoid (11). Previous reports showed that ATRA inhibits the estrogen-induced proliferation of several cell types in in vitro and in vivo assays (1214). In addition, ATRA expresses receptor-mediated antiestrogenic activity and interferes with estrogenic activity at the estrogen-responsive-element (ERE) level $(15,16)$.

The subcutaneous injection of BPA into neonatal male mice resulted in a decrease in their sperm motility and an increase in the incidence of malformed sperm after the mice became adults, and this BPA effect was cancelled by cotreatment with retinol acetate, a natu-

E-mail: imahide@med.miyazaki-u.ac.jp rally occurring metabolite of vitamin A (17). However, the effects of ATRA on the BPA-induced biological effects in adult female rats have not been investigated. In this study, we examined the inhibitory effect of ATRA on the estrogenic activity of BPA by a standard in vivo uterotrophic assay that was authorized by the Organization for Economic Cooperation and Development (OECD) (18). Exogenous estrogens have been shown to induce hypertrophy, predominantly of the luminal epithelium but also of the glandular epithelium (19-21), and the proliferation of the stroma (22) and myometrium $(23,24)$ in rodents. Bisphenol A-induced increases in the thicknesses of both stromal and myometrial layers are not mediated through ER (25). Therefore, we examined the degrees of proliferation and apoptosis of the uterine epithelial cells by 5-bromo$2^{\prime}$ deoxyuridine (BrdU) incorporation and terminal deoxynucleotidyl transferase (TdT)-mediated dUTP nick end labeling (TUNEL) assay, respectively.

\section{Materials and Methods}

Chemicals. Bisphenol A (CAS No. 80-05-7) was obtained from Sigma-Aldrich Corporation (MO, USA). All-trans-retinoic acid (CAS No. 302-70-4) was purchased from Wako Pure Chemical Industries, Ltd. (Osaka, Japan). Olive oil (for dissolving ATRA) was obtained from Nacalai Tesque Inc. (Kyoto, Japan). Pen- 
tobarbital (Nembutal ${ }^{\circledR}$, Abbott Laboratories, IL, USA) was purchased from Dainippon Pharmaceutical Co., Ltd. (Osaka, Japan). Bisphenol A or ATRA was dissolved in olive oil and injected subcutaneously at a volume of 1 $\mathrm{mL} / \mathrm{kg}$ body weight (b.w.).

Animals. Female Crj:CD (SD) rats (10-11 wk old) were purchased from Charles River Japan (Ibaraki, Japan). The rats were housed in metal cages with a 12h light/dark cycle (beginning at 7:00 a.m.), and given free access to commercial food (CE-2, CLEA Japan Inc., Tokyo, Japan) and tap water. The rats were ovariectomized under pentobarbital anesthesia $(50 \mathrm{mg} / \mathrm{kg} \mathrm{b.w.)}$ and allowed to recover for $2 \mathrm{wk}$.

All experiments were conducted in accordance with the guidelines of the Ethics Committee for Experimental Animals of the National Institute for Environmental Studies, Japan.

Uterotrophic assay. The rats were treated with 100 $\mathrm{mg} / \mathrm{kg}$ b.w./d BPA with or without $5 \mathrm{mg} / \mathrm{kg}$ b.w./d ATRA subcutaneously between 9:00 and 10:00 a.m. once a day for 3 successive days. Twenty-four hours after the last treatment, the rats were sacrificed and uteri were removed immediately. After being cut into small pieces, the uteri were placed on a Kimwipe ${ }^{\circledR}$ and gently pressed to blot the fluid. Blotted-uterus weight was recorded and expressed as $\mathrm{mg} / 100 \mathrm{~g} \mathrm{b.w}$. All the rats were injected with $40 \mathrm{mg} / \mathrm{kg}$ b.w. BrdU (Sigma-Aldrich) intraperitoneally 8 -h before being sacrificed. This adopted procedure was performed in accordance with the OECD protocol (18).

Tissue preparation. The blotted uteri were placed in a neutral $10 \%$ formaldehyde buffer solution (Nacalai Tesque, Inc.) for 12-h at room temperature and then dehydrated and embedded in paraffin. Transverse sections were cut into 5 - $\mu$ m-thick sections using a microtome (LEICA Microsystems Japan, Tokyo) and mounted on MAS-coated slides.

Determination of cell proliferation. To detect uterine cell proliferation, the cellular incorporation of the injected BrdU was determined using a DAKO $\mathrm{LSAB}^{\circledR} 2$ kit (Dako Corporation, CA, USA) according to the manufacturer's instruction. Briefly, the BrdU incorporated into the uterine cells was immunostained and finally visualized with 3,3'-diaminobenzidine (DAB) (Roche Diagnostics Corporation, IN, USA). The preparations were counterstained with hematoxylin after immunostaining. For a quantitative evaluation, the number of BrdU-positive cells and the total numbers of luminal and glandular epithelial cells were counted under a microscope $(400 \times)$, and the percentage of BrdU-positive cells was calculated.

Determination of cell death. Apoptotic uterine cells were analyzed by TUNEL assay using an ApopTag ${ }^{\circledR}$ Peroxidase In Situ Apoptosis Detection kit (Chemicon, CA, USA). Briefly, digoxigenin-nucleotide residues were catalytically added to the 3'-OH ends of double- or singlestranded DNAs by utilizing TdT. The labeled cells were visualized using DAB. The slides were counterstained with methyl green after immunostaining. For a quantitative evaluation, the number of TUNEL-positive cells and the total numbers of luminal and glandular epithelial cells were counted under a microscope $(400 \times)$ and the percentage of TUNEL-positive cells was calculated.

Statistical analysis. Dunnett's test was employed to analyze blotted-uterus weight, and the percentages of BrdU- and TUNEL-positive cells.

\section{Results and Discussion}

Bisphenol A treatment significantly increased blotted-uterus weight/100 g b.w. (vehicle: $39.9 \mathrm{mg} / 100 \mathrm{~g}$ b.w.; BPA: $81.0 \mathrm{mg} / 100 \mathrm{~g}$ b.w., $p<0.01)$. The coinjection of ATRA significantly decreased the BPA-induced increase in blotted-uterus weight/100 g b.w. (BPA+ ATRA: $69.3 \mathrm{mg} / 100 \mathrm{~g}$ b.w., $p<0.05)$. There was no significant difference in blotted-uterus weight/100 g b.w. between the vehicle and ATRA (ATRA: $44.2 \mathrm{mg} / 100 \mathrm{~g}$ b.w.) groups (Fig. 1). We showed here that ATRA treatment significantly inhibits the BPA-induced uterotrophic effect. Several animal experimental studies have shown the effects of exogenous estrogens on the uterus including hypertrophy, predominantly of the luminal epithelium but also of the glandular epithelium (1921 ), and the proliferation of the stroma (22) and myometrium $(23,24)$. It is likely that the changes in the weight of stromal and myometrial cells contribute to the increase in uterine weight. In one study, BPA was shown to induce increases in uterine weight, luminal epithelial cell height and the thicknesses of both the stroma and myometrium (25). In the same study, it was shown that the coadministration of the antiestrogen ICI 182,780 reverses the effect on epithelial cell height; however, the thicknesses of the stromal and myometrial layers were not influenced (25). Nephew et al. reported that estradiol $17 \beta$-induced changes in ER $\alpha$ protein synthesis occurred in the luminal and glandular epithelia, but did not occur in either the stromal cells or the myometrial cells in adult ovariectomized rats (26). Therefore, the enlargements of the stroma and myo-

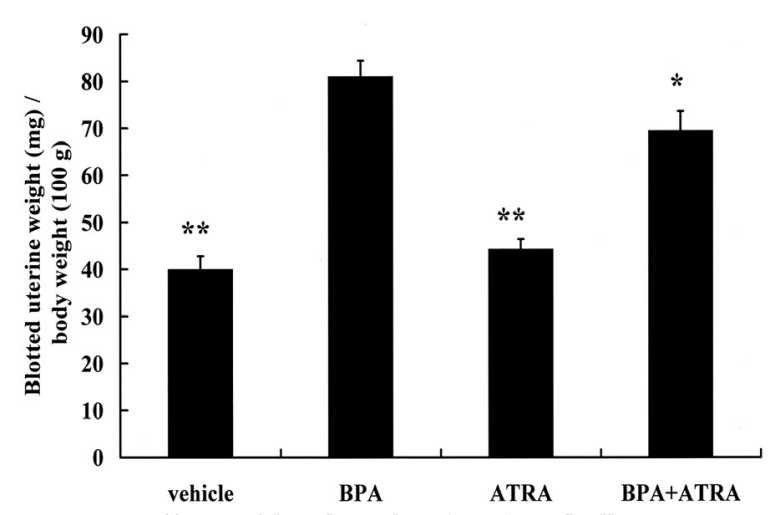

Fig. 1. Effects of bisphenol A (BPA) and all-trans-retinoic acid (ATRA) on blotted-uterus weight/100 g b.w. in ovariectomized rats. The vertical axis shows the blotted-uterus weight $/ 100 \mathrm{~g}$ b.w. The horizontal axis shows treatment chemicals. Columns indicate mean values and vertical lines denote the standard errors of the mean (SE). Each column represents five or six rats. ${ }^{*} p<$ $0.05,{ }^{* *} p<0.01$ versus BPA group by Dunnett's test. 
A

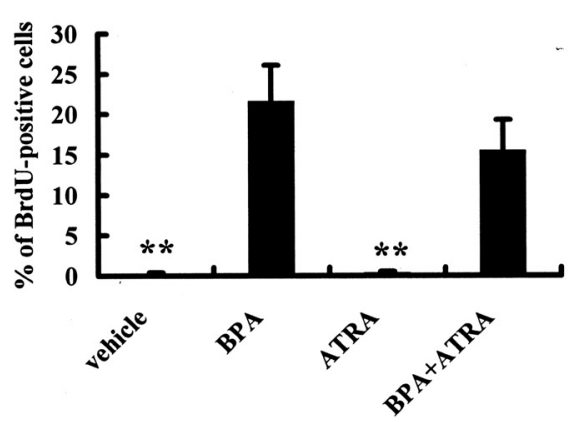

$\mathbf{C}$

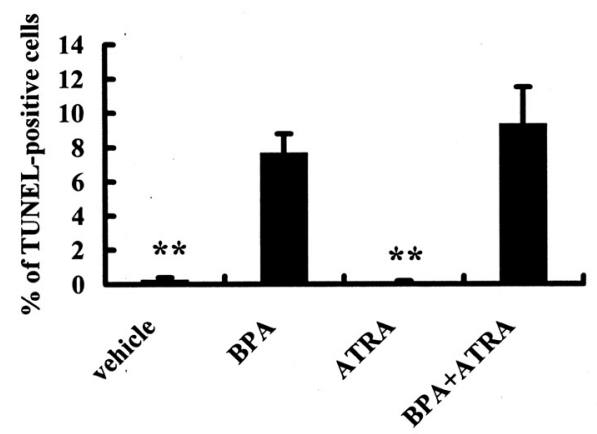

B

Glandular epithelium cells

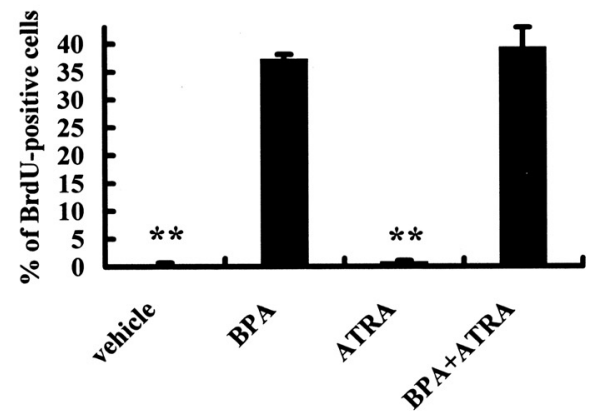

D Glandular epithelium cells

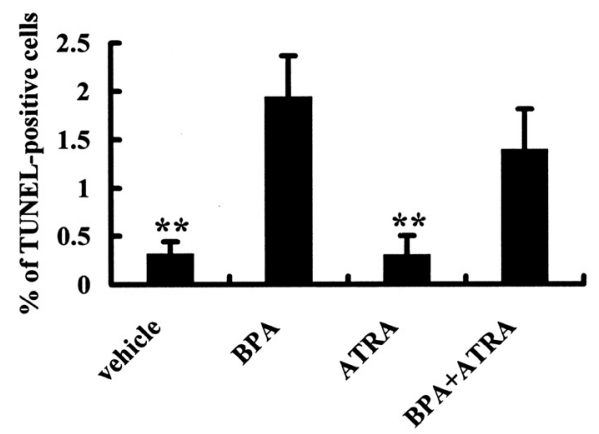

Fig. 2. Effects of bisphenol A (BPA) and all-trans-retinoic acid (ATRA) on numbers of BrdU-positive (A, B) and TUNEL-positive (C, D) cells in the luminal and glandular epithelia. The vertical axis shows the percentage of positive cells. The horizontal axis shows treatment chemicals. Columns indicate mean values and vertical lines denote the standard errors of the mean (SE). Each column represents five or six rats. ${ }^{* *} p<0.01$ versus BPA group by Dunnett's test.

metrium could be attributable to other mechanisms not mediated via ER. Thus, we examined the cell proliferation and cell apoptosis in luminal and glandular epithelial cells.

Bisphenol A treatment with or without ATRA treatment induced cell proliferation, as revealed by BrdU immunostaining both in the luminal and glandular epithelial cells (Fig. 2, A and B). The mean percentages of BrdU-positive cells in the luminal and glandular epithelia significantly increased as a result of BPA treatment (vehicle: luminal epithelium, $0.23 \%$ and glandular epithelium, 0.48\%; BPA: luminal epithelium, $21.6 \%$ and glandular epithelium, $37.4 \%$ ). There was no significant difference in the mean percentages of BrdU-positive cells in the luminal and glandular epithelia between the BPA and BPA+ATRA (luminal epithelium, 15.5\%; glandular epithelium, $39.4 \%$ ) groups or between the vehicle and ATRA (luminal epithelium, $0.38 \%$; glandular epithelium, 0.85\%) groups (Fig. 2, A and B).

Bisphenol A treatment with or without ATRA treatment induced the apoptosis of luminal and glandular epithelial cells, as revealed by TUNEL assay. The mean percentages of TUNEL-positive cells in the luminal and glandular epithelia significantly increased as a result of BPA treatment (vehicle: luminal epithelium, $0.27 \%$ and glandular epithelium, $0.32 \%$; BPA: luminal epithelium, $7.7 \%$ and glandular epithelium, $1.9 \%$ ). There was no significant difference in the mean percentages of TUNEL-positive cells in the luminal and glandular epithelia between the BPA and BPA+ATRA (luminal epithelium, 9.4\%; glandular epithelium, $1.4 \%$ ) groups, or between the vehicle and ATRA (luminal epithelium, 0.11\%; glandular epithelium, 0.31\%) groups (Fig. 2, C and D).

Previous studies showed that ATRA treatment inhibits estrogen-induced cell proliferation in in vitro and in vivo assays (12-14). All-trans-retinoic acid was suggested to inhibit the growth of human breast cancer cells by promoting apoptosis (27). Our results indicate that the mean percentage of proliferated luminal epithelium cells in the BPA group was significantly larger than that in the vehicle group. The mean percentage of proliferated luminal epithelium cells in the BPA+ATRA group was smaller than that in the BPA group; however, the difference did not reach statistical significance. We performed BrdU incorporation to detect the proliferation of cells. This method can detect S-phase cells, but not G1- , G2- or M-phase cells. Other methods of detecting the proliferation of cells in all phases, such as Ki-67 immunostaining (28), may show a difference in the mean percentage of proliferating cells between the BPA and BPA+ATRA groups. There was no significant difference in the mean percentages of proliferating glandular epithelial cells between the BPA and BPA+ATRA 
groups. Because the number of luminal epithelium cells was markedly larger than that of glandular epithelium cells, the number of luminal epithelium cells may have a profound effect on uterine weight. The mean percentage of apoptotic luminal epithelium cells in the BPA group was significantly larger than that in the vehicle group. The mean percentage of apoptotic luminal epithelium cells in the BPA + ATRA group was larger than that in the BPA group; however, the difference did not reach statistical significance.

Bisphenol A was found to bind to $\operatorname{ER} \alpha(6)$ and induce the proliferation of MCF-7 cells (29) and the transcriptional activation of the ER in a yeast-based assay (7). However, estrogen and BPA have different effects on ER $\alpha$, ER $\beta$ and C3 expressions in the uterus (30). Mechanisms other than the ER-mediated pathway may be involved in these different effects; alternatively, BPA may act via ER $\alpha$ or ER $\beta$ but may activate in addition to the enhancers or repressors of ER activities in the uterus (30).

Further study is necessary to clarify the inhibitory mechanisms of ATRA on BPA in uteri.

\section{Acknowledgments}

The authors thank Dr. Junzo Yonemoto (National Institute for Environmental Studies) and Dr. Yoshihiro Shidoji (Siebold University of Nagasaki) for helpful comments on this manuscript.

\section{REFERENCES}

1) Staples CA, Dorn PB, Klecka GM, O'Block ST, Harris LR. 1998. A review of the environmental fate, effects, and exposures of bisphenol A. Chemosphere 36: 2149-2173.

2) Steinmetz R, Brown NG, Allen DL, Bigsby RM, BenJonathan N. 1997. The environmental estrogen bisphenol A stimulates prolactin release in vitro and in vivo. Endocrinology 138: 1780-1786.

3) Krishnan AV, Stathis P, Permuth SF, Tokes L, Feldman D. 1993. Bisphenol-A: an estrogenic substance is released from polycarbonate flasks during autoclaving. Endocrinology 132: 2279-2286.

4) Brotons JA, Olea-Serrano MF, Villalobos M, Pedraza V, Olea N. 1995. Xenoestrogens released from lacquer coatings in food cans. Environ Health Perspect 103: 608 612.

5) Koda T, Umezu T, Kamata R, Morohoshi K, Ohta T, Morita M. 2005. Uterotrophic effects of benzophenone derivatives and a $p$-hydroxybenzoate used in ultraviolet screens. Environ Res 98: 40-45.

6) Koda T, Soya Y, Negishi H, Shiraishi F, Morita M. 2002. Improvement of a sensitive enzyme-linked immunosorbent assay for screening estrogen receptor binding activity. Environ Toxicol Chem 21: 2536-2541.

7) Gaido KW, Leonard LS, Lovell S, Gould JC, Babai D, Portier CJ, McDonnell DP. 1997. Evaluation of chemicals with endocrine modulating activity in a yeast-based steroid hormone receptor gene transcription assay. Toxicol Appl Pharmacol 143: 205-212.

8) Sporn MB, Roberts AB. 1983. Role of retinoids in differentiation and carcinogenesis. Cancer Res 43: 3034 3040 .

9) Vermot J, Fraulob V, Dolle P, Niederreither K. 2000.
Expression of enzymes synthesizing (aldehyde dehydrogenase 1 and retinaldehyde dehydrogenase 2) and metabolizing (Cyp26) retinoic acid in the mouse female reproductive system. Endocrinology 141: 3638-3645.

10) Zheng WL, Bucco RA, Sierra-Rievera E, Osteen KG, Melner MH, Ong DE. 1999. Synthesis of retinoic acid by rat ovarian cells that express cellular retinoic acid-binding protein-II. Biol Reprod 60: 110-114.

11) McCormick AM, Napoli JL. 1982. Identification of 5,6epoxyretinoic acid as an endogenous retinol metabolite. J Biol Chem 257: 1730-1735.

12) Fontana JA, Miranda D, Mezu AB. 1990. Retinoic acid inhibition of human breast carcinoma proliferation is accompanied by inhibition of the synthesis of a $\mathrm{Mr}$ 39,000 protein. Cancer Res 50: 1977-1982.

13) Muller P, Kietz S, Gustafsson JA, Strom A. 2002. The anti-estrogenic effect of all-trans-retinoic acid on the breast cancer cell line MCF-7 is dependent on HES-1 expression. J Biol Chem 277: 28376-28379.

14) Boettger-Tong HL, Stancel GM. 1995. Retinoic acid inhibits estrogen-induced uterine stromal and myometrial cell proliferation. Endocrinology 136: 2975-2983.

15) Demirpence E, Balaguer P, Trousse F, Nicolas JC, Pons M, Gagne D. 1994. Antiestrogenic effects of all-transretinoic acid and 1,25-dihydroxyvitamin D3 in breast cancer cells occur at the estrogen response element level but through different molecular mechanisms. Cancer Res 54: 1458-1464.

16) Takeyoshi M, Yamasaki K, Sawaki M, Nakai M, Noda S, Takatsuki M. 2002. The efficacy of endocrine disruptor screening tests in detecting anti-estrogenic effects downstream of receptor-ligand interactions. Toxicol Lett 126: 91-98.

17) Aikawa H, Koyama S, Matsuda M, Nakahashi K, Akazome Y, Mori T. 2004. Relief effect of vitamin A on the decreased motility of sperm and the increased incidence of malformed sperm in mice exposed neonatally to bisphenol A. Cell Tissue Res 315: 119-124.

18) Kanno J, Onyon L, Haseman J, Fenner-Crisp P, Ashby J, Owens W. 2001. The OECD program to validate the rat uterotrophic bioassay to screen compounds for in vivo estrogenic responses: phase 1. Environ Health Perspect 109: $785-794$.

19) Branham WS, Zehr DR, Sheehan DM. 1993. Differential sensitivity of rat uterine growth and epithelium hypertrophy to estrogens and antiestrogens. Proc Soc Exp Biol Med 203: 608-612.

20) Cooke PS, Buchanan DL, Young P, Setiawan T, Brody J, Korach KS, Taylor J, Lunbahn DB, Cunha GR. 1997. Stromal estrogen receptors mediate mitogenic effects of estradiol on uterine epithelium. Proc Natl Acad Sci USA 94: 6535-6540.

21) Katsuda SI, Yoshida M, Watanabe T, Kuroda H, Ando-Lu J, Takahashi M, Hayashi H, Maekawa A. 1999. Estrogen receptor mRNA in uteri of normal estrous cycling and ovariectomized rats by in situ hybridization. Proc Soc Exp Biol Med 221: 207-214.

22) Cook JC, Kaplan M, Davis LG, O'Connor JC. 1997. Development of a Tier 1 screening battery for detecting endocrine-active compounds (EACs). Reg Toxicol Pharmacol 26: 60-68.

23) Hunter DS, Hodges LC, Vonier PM, Fuchs-Young R, Gottardis MM, Walker CL. 1999. Estrogen receptor activation via activation function 2 predicts agonism of xenoestrogens in normal and neoplastic cells of the 
uterine myometrium. Cancer Res 59: 3090-3099.

24) Yokoyama Y, Takahashi Y, Hashimoto M, Shinohara A, Lian Z, Tamaya T. 1998. Effects of sex steroids on silver stained proteins of nucleolar organizer regions $(\mathrm{Ag}-$ NOR) in the rabbit uterus. Biotech Histochem 73: 202210.

25) Papaconstantinou AD, Umbreit TH, Fisher BR, Goering PL, Lappas NT, Brown KM. 2000. Bisphenol A-induced increases in uterine weight and alternations in uterine morphology in ovariectomized B6C3F1 mice: role of estrogen receptor. Toxicol Sci 56: 332-339.

26) Nephew KP, Long X, Osborne E, Burke KA, Ahluwalia A, Bigsby RM. 2000. Effect of estradiol on estrogen receptor expression in rat uterine cell types. Biol Reprod 62: $168-177$.

27) Liu Y, Lee MO, Wang HG, Li Y, Hashimoto Y, Klaus M, Reed JC, Zhang X. 1996. Retinoic acid receptor beta mediates the growth-inhibitory effect of retinoic acid by promoting apoptosis in human breast cancer cells. Mol Cell Biol 16: 1138-1149.

28) Ohta Y, Ichimura K. 2000. Proliferation markers, proliferating cell nuclear antigen, Ki67, 5-bromo-2'-deoxyuridine, and cyclin D1 in mouse olfactory epithelium. Ann Otol Rhinol Laryngol 109: 1046-1048.

29) Diel P, Olff S, Schmidt S, Michna H. 2002. Effects of the environmental estrogens bisphenol A, o, $p^{\prime}$-DDT, $p$-tertoctylphenol and coumestrol on apoptosis induction, cell proliferation and the expression of estrogen sensitive molecular parameters in the human breast cancer cell line MCF-7. J Steroid Biochem Mol Biol 80: 61-70.

30) Seidlova-Wuttke D, Jarry H, Wuttke W. 2004. Pure estrogenic effect of benzophenone-2 (BP2) but not of bisphenol A (BPA) and dibutylphtalate (DBP) in uterus, vagina and bone. Toxicology 205: 103-112. 